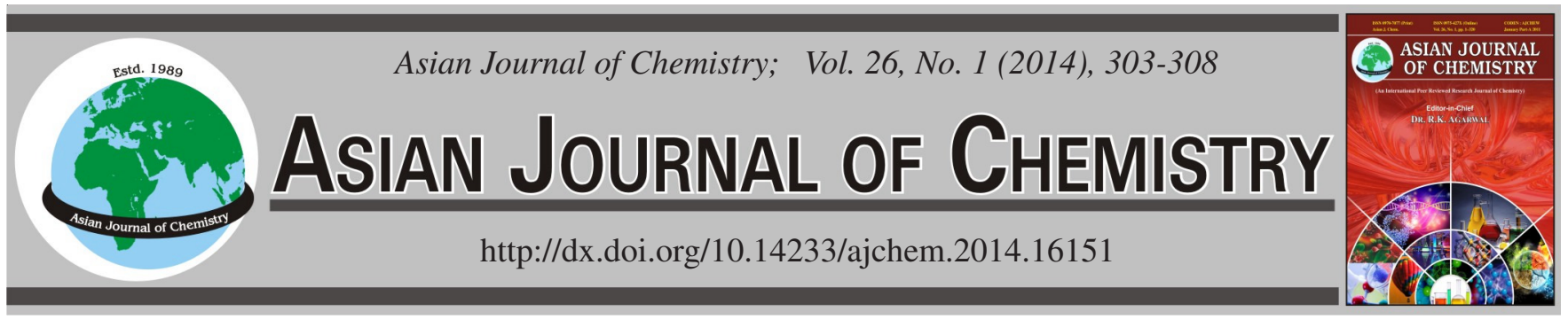

\title{
Adsorption of Nitenpyram and Acetamiprid on Modified Resin with Proline
}

\author{
Xiuhong Wu*, Xuehua Zhang, Hongmei Zhang, Gencheng Zhang and Zhenghao Fei
}

Jiangsu Provincial Key Laboratory of Coastal Wetland Bioresources and Environmental Protection, College of Chemistry and Chemical Engineering, Yancheng Teachers University, Yancheng 224051, P.R. China

*Corresponding author: Fax: +86 515 88233188; Tel: +86 15050663330; E-mail: sunnywuxh@163.com

\begin{abstract}
The adsorption behaviour of nitenpyram and acetamiprid in water onto the resin modified with proline based was investigated by static adsorption experiments at different temperature $(288,303$ and $318 \mathrm{~K})$ in single component and binary components system. The adsorption capacities and adsorption selectivity for acetamiprid in water were tested. The results showed the adsorption was fitted better by Freundlich model than Langmuir model in single system. The adsorption of nitenpyram on the resin modified with proline was an endothermic process by the positive adsorption enthalpy and an exothermic process of acetamiprid with the negative adsorption enthalpy. Entropy change was giving a friendly boost to adsorption. The resin had better absorbability for acetamiprid than for nitenpyram and the adsorption selectivity of acetamiprid was larger than one at lower temperature as well as at lower concentrations. A high removal rate of 45.56-82.66 $\%$ was obtained for nitenpyram studied and the removal rate of acetamiprid was in the range of 48.77-86.23\% in single component system. In binary components system the removal rate of acetamiprid was higher, lower for nitenpyram, because of competition in adsorption site. The equilibrium adsorption isotherms of both nitenpyram and acetamiprid in binary components system were fitted better by Langmuir model. So the adsorption of nitenpyram and acetamiprid on the resin modified with proline was on the monolayer adsorption in binary components system. But the cooperative effect existed at $318 \mathrm{~K}$. In additional studies, the competitive adsorption existed. The adsorption of acetamiprid onto the resin had just smaller change in the presence of nitenpyram, but the adsorption of nitenpyram was weakened obviously in the presence of acetamiprid. The adsorption selectivity of acetamiprid on the resin is larger than one on lower temperature with lower concentrations.
\end{abstract}

Keywords: Adsorption resin, Nitenpyram, Acetamiprid, Proline.

\section{INTRODUCTION}

Pesticides are widely used in the world. Nitenpyram and acetamiprid are new nicotine insecticide with high and fast effectiveness, destroys insects widely, has a persistent efficiency period and better solubility under room temperature ${ }^{1}$, used in agriculture. For the natural waters, they are likely to be contaminated with nitenpyram and acetamiprid. There is a serious need for the high-tech about the economic, efficient, feasible water treatment, to protect them. Resin adsorption is widely used in wastewater treatment ${ }^{2-6}$, which makes resin adsorption technology has irreplaceable characteristics because of the designability and selectivity of resin's chemical or physical structures on practical applications ${ }^{7}$. The adsorption rule is complicated in binary component system in aqueous solution and some papers were reported ${ }^{8-13}$. The paper focuses on the adsorption of nitenpyram and acetamiprid in aqueous solution on the resin modified with proline ${ }^{14}$ and the adsorption behaviour and adsorption selectivity of two pollutants coexisting in water, modified adsorption resin as adsorbent, nitenpyram and acetamiprid as adsorbates through static adsorption. A thermodynamical study is made. These data will provide reference for theory research and engineering design. Schemes I and II is the structure of nitenpyram and acetamiprid.<smiles>CCC(Cc1ccc(Cl)nc1)/C(=C/[N+](=O)[O-])NC</smiles>

Scheme-I: Structure of nitenpyram<smiles>C/C(=N\C#N)N(C)Cc1ccc(Cl)nc1</smiles>

Scheme-II: Structure of acetamiprid 


\section{EXPERIMENTAL}

Methanol is of G.R. grade. Both acetamiprid and nitenpyram are of A.R. grade and the resin of is modified with proline based on NDA $150^{14}$.

Static adsorption experiment: A bottle point isotherm procedure was used to conduct all the equilibrium studies in single component system. $0.100 \mathrm{~g}$ of the resin was directly weighed accurately. The adsorbents were contacted, in $250 \mathrm{~mL}$ stoppered conical flasks, with $100 \mathrm{~mL}$ of nitenpyram or acetamiprid solution of certain concentration $\left(\mathrm{C}_{0}, \mathrm{mg} / \mathrm{L}\right)$ ranging from 200 to $600 \mathrm{mg} / \mathrm{L}$. The flasks were completely sealed and then placed in an incubator shaker at different temperatures (288, 303 and $318 \mathrm{~K}$ ) until the equilibrium was achieved.

Experiments of binary system were performed according to the above procedure. The main difference was that the initial concentrations of nitenpyram and acetamiprid were equal to each other at the concentration of 100, 150, 200, 250 and $300 \mathrm{mg} / \mathrm{L}$. Other binary solute isotherms were also performed following the above procedure. The difference was that the initial concentrations of nitenpyram were constant at 400 $\mathrm{mg} / \mathrm{L}$ and the initial concentrations of acetamiprid were at 200, $300,400,500$ and $600 \mathrm{mg} / \mathrm{L}$. Conversely, the initial concentrations of acetamiprid were constant at $400 \mathrm{mg} / \mathrm{L}$.

\section{RESULTS AND DISCUSSION}

Static adsorption of nitenpyram and acetamiprid in single component system: Equilibrium adsorption isotherms of nitenpyram and acetamiprid onto the resin in single component system were presented in Fig. 1. The isotherm corresponding to higher temperature laid above, which showed the endothermic process, with higher adsorption amounts at higher temperature for nitenpyram, but for acetamiprid, the exothermic process. In Fig. 1, at the same equilibrium concentration, the resin has stronger adsorbability at acetamiprid.

A high removal rate of 45.56-82.66 \% was obtained for nitenpyram studied, as shown in Fig. 2 and the removal rate of acetamiprid was in the range of 48.77-86.23\%. Removal rate was higher with higher temperature for nitenpyram. Contrary to nitenpyram, removal rate was lower with lower temperature for acetamiprid. The result corresponded with the equilibrium adsorption isotherms in Fig. 1.

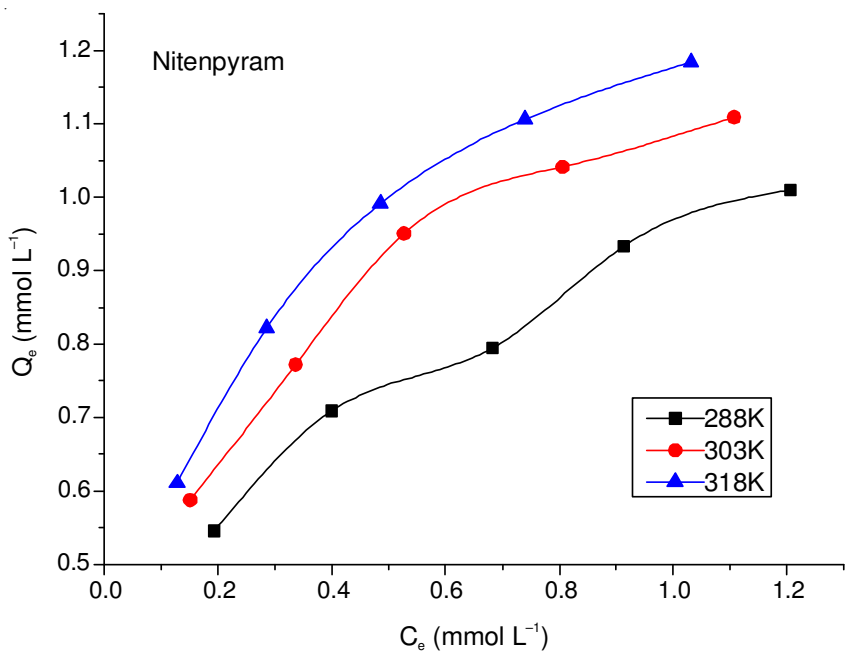

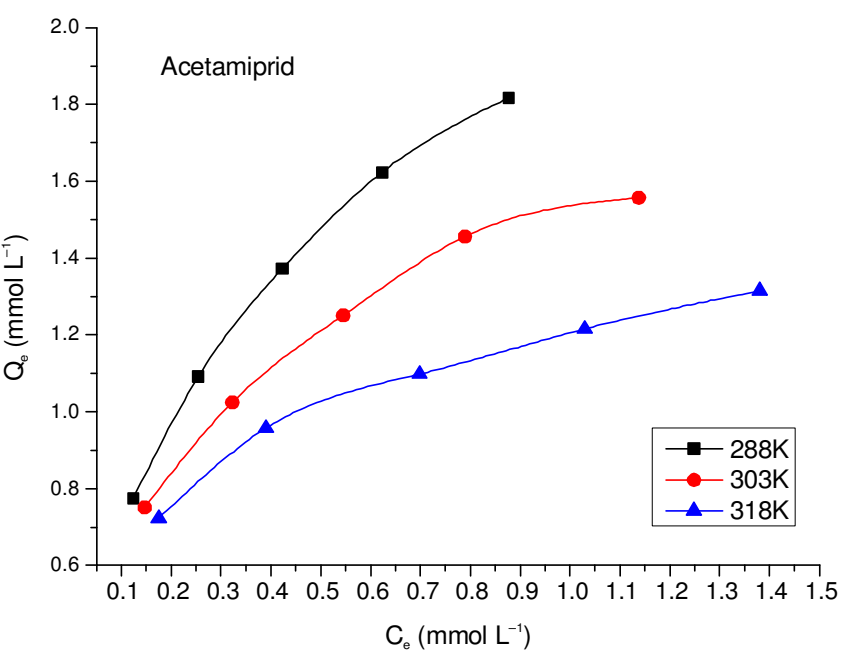

Fig. 1. Equilibrium adsorption isotherms of nitenpyram and acetamiprid in single component system on the resin at $288-318 \mathrm{~K}$
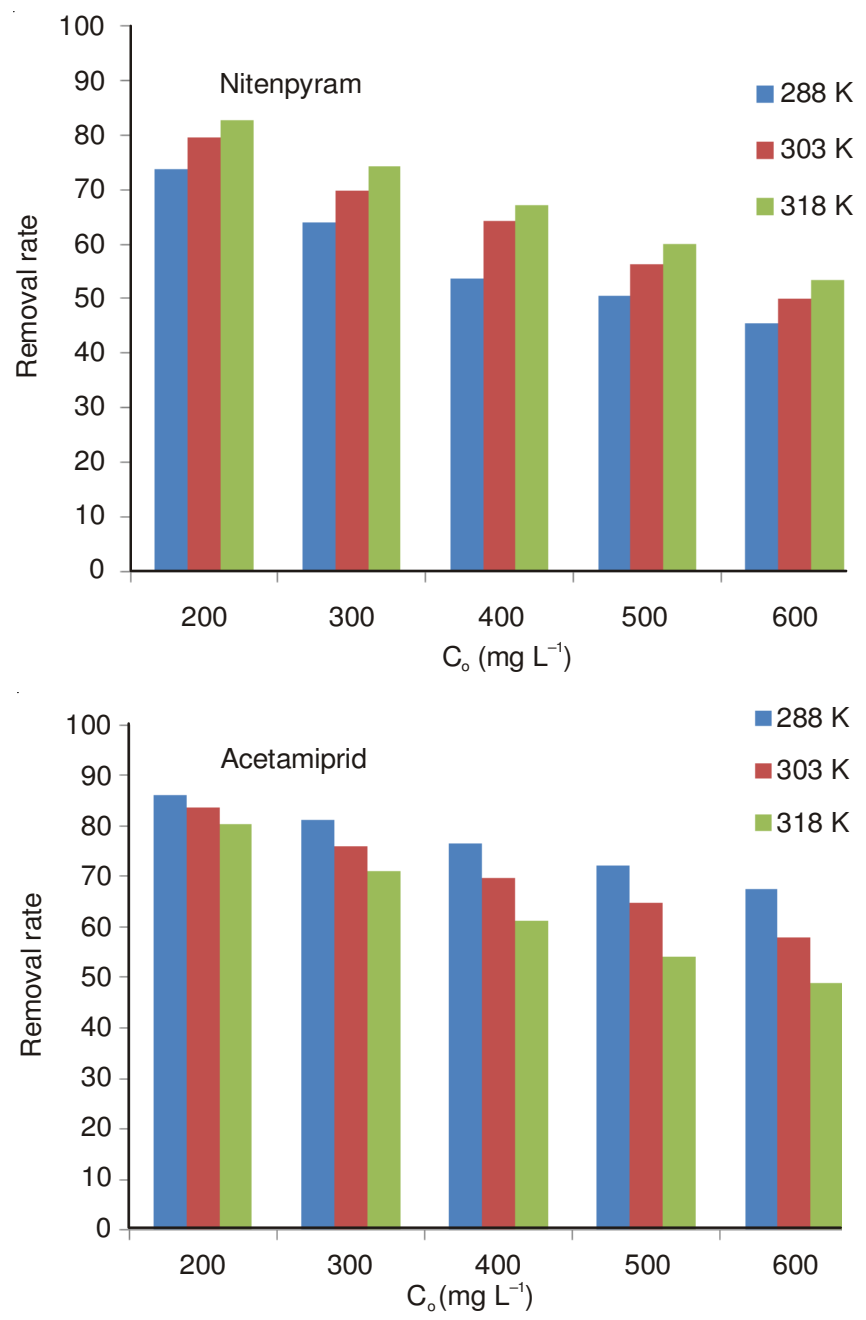

Fig. 2. Removal rate of nitenpyram or acetamiprid at different temperatures and initial solute concentrations in single component system

Many theories, used to model the adsorption process, have been proposed to explain the adsorption phenomenon and to describe the adsorption isotherm relationships. Among them the Langmuir and Freundlich models have been widely used and their linear forms are given below respectively ${ }^{14}$.

$$
\text { Langmuir model: } 1 / \mathrm{Q}_{\mathrm{e}}=1 /\left(\mathrm{C}_{\mathrm{e}} \mathrm{MK}_{\mathrm{L}}\right)+1 / \mathrm{M}
$$


Freundlich model: $\log \mathrm{Q}_{\mathrm{e}}=\log \mathrm{K}_{\mathrm{f}}+1 / \mathrm{n} \log \mathrm{C}_{\mathrm{e}}$

Corresponding equations were given with computer fitting. And their constants along with the correlation coefficients ' $r$ ' are summarized in Table-1. The results clearly show that the adsorption data for the studied adsorption systems of nitenpyram fits better to the Freundlich and Langmuir model and to acetamiprid, too. The sorption mechanism was more complex.

As seen from the values of $M, K_{L}, K_{f}, n$ in Table-1, the capacity of nitenpyram increases with increasing initial concentration and temperature for the interaction between basic groups of nitenpyram and acid groups on the resin modified with proline, chemisorption processes existed in processes. Conversely, $\mathrm{M}, \mathrm{K}_{\mathrm{f}}$ of acetamiprid decreases with the increasing temperature, physical absorption existed. And the constant $n$ was always more than 1 in our study range, indicating a favourable type adsorption.

Thermodynamics: Thermodynamic parameters such as Gibbs free energy $(\Delta \mathrm{G})$, enthalpy change $(\Delta \mathrm{H})$ and entropy change $(\Delta S)$ for the adsorption of nitenpyram and acetamiprid onto the resin are given in Table- $2 . \Delta \mathrm{G}$ is calculated according to eqn. 3 , for the data onto the resin better fitted to the Freundlich model. And so the calculation of $\Delta \mathrm{G}$ in binary components system is the same as in single component system.

$$
\Delta \mathrm{G}=-\mathrm{n} \text { RT }
$$

where $\mathrm{n}$ is the Freundlich model characteristic constant, $\mathrm{R}$ is the gas constant $(\mathrm{kJ} / \mathrm{mol} \mathrm{K})$ and $\mathrm{T}$ is the absolute temperature (K).

The following Gibbs-Helmholtz equation can be obtained to describe the relation between $\Delta \mathrm{G}$ and the other two thermodynamic parameters.

$$
\Delta \mathrm{G}=\Delta \mathrm{H}-\mathrm{T} \Delta \mathrm{S}
$$

Then, $\Delta \mathrm{H}$ can be calculated respectively from the van't Hoff equation.

$$
\ln \left(\mathrm{Q}_{\mathrm{e}} / \mathrm{C}_{\mathrm{e}}\right)=-\Delta \mathrm{H} / \mathrm{RT}+\ln \mathrm{K}_{0}
$$

The estimated enthalpy of adsorption of nitenpyram is positive, indicating the adsorption process is an endothermic one. The enthalpy of acetamiprid is negative, an exothermic process. Both are low and in the range of $10-40 \mathrm{~kJ} / \mathrm{mol}$ where physical adsorption is expected to be the dominant mechanism. It is well known that the free energy change value for a physical sorption, which is in the range of -20 to $0 \mathrm{~kJ} / \mathrm{mol}$. A chemical sorption process is in the range of -400 to $-80 \mathrm{~kJ} / \mathrm{mol}$. $\Delta \mathrm{G}$ was small, shown in Table-2, further confirming the physical character of the adsorption. And as expected they were negative in processes. The values of the adsorption entropy were positive. For the resin with the multi-pore structure and functional groups, has powerful water absorption. So in lower temperature the water molecules were adsorbed preferentially then with the different interactions changing, nitenpyram or acetamiprid was adsorbed little by little, with the more desorptions of water molecules, because the molecular size of nitenpyram or acetamiprid is higher than water molecule. That's solute-solvent measurement replacement. Then the entropy-increase effect, gave a friendly boost.

Same initial concentration of nitenpyram and acetamiprid in binary components system: Equilibrium adsorption isotherms of nitenpyram and acetamiprid onto the resin in binary components system are presented in Fig. 3. The effect of the temperature cohered with it in single component system (Fig. 1). Comparing with Fig. 1, equilibrium adsorption isotherms of nitenpyram or acetamiprid in binary components system changed irregularly. For example, the adsorptive capacity of nitenpyram at the initial concentration $\left(250\right.$ and $300 \mathrm{mg} \mathrm{L}^{-1}$ ) decreased greatly, because of the existence of acetamiprid. The coexistence of nitenpyram or acetamiprid in water caused the competition on the resin.

High removal rate was obtained for nitenpyram studied from Fig. 4, in the range of 25.91-82.24 \%, lower than it in single component system. But for acetamiprid removal rate was higher in the range of 67.04-92.30\%, being improved better than it in single component system.

\begin{tabular}{|c|c|c|c|c|c|c|c|c|c|}
\hline \multirow{2}{*}{ Adsorbate } & \multirow{2}{*}{$\begin{array}{c}\text { Temp. } \\
(\mathrm{K})\end{array}$} & \multicolumn{4}{|c|}{ Langmuir } & \multicolumn{4}{|c|}{ Freundlich } \\
\hline & & Equation & $\mathrm{M}$ & $\mathrm{K}_{\mathrm{L}}$ & $r$ & Equation & $\mathrm{K}_{\mathrm{f}}$ & $\mathrm{n}$ & $\mathrm{r}$ \\
\hline \multirow{3}{*}{ Nitenpyram } & 288 & $Y=0.1854 x+0.9027$ & 1.108 & 4.869 & 0.983 & $Y=0.3329 x-0.0254$ & 0.943 & 3.004 & 0.994 \\
\hline & 303 & $Y=0.1398 x+0.8008$ & 1.249 & 5.728 & 0.991 & $Y=0.3283 x+0.046$ & 1.112 & 3.046 & 0.991 \\
\hline & 318 & $Y=0.1146 x+0.7624$ & 1.312 & 6.653 & 0.995 & $Y=0.322 x+0.0831$ & 1.211 & 3.105 & 0.995 \\
\hline \multirow{3}{*}{ Acetamiprid } & 288 & $Y=0.1052 x+0.4602$ & 2.173 & 4.374 & 0.995 & $Y=0.4405 x+0.2952$ & 1.961 & 2.270 & 0.998 \\
\hline & 303 & $Y=0.1153 x+0.5668$ & 1.764 & 4.916 & 0.992 & $Y=0.3667 x+0.1877$ & 1.541 & 2.727 & 0.996 \\
\hline & 318 & $Y=0.1207 x+0.7097$ & 1.413 & 5.880 & 0.994 & $Y=0.2853 x+0.0834$ & 1.212 & 3.505 & 0.996 \\
\hline
\end{tabular}

TABLE-1

FITTED RESULTS FOR LANGMUIR AND FREUNDLICH MODELS IN SINGLE COMPONENT SYSTEM

TABLE-2

\begin{tabular}{|c|c|c|c|c|c|}
\hline Adsorbate & $\mathrm{q}_{\mathrm{e}}(\mathrm{mmol} / \mathrm{g})$ & Temperature $(\mathrm{K})$ & $\Delta \mathrm{H}(\mathrm{kJ} / \mathrm{mol})$ & $\Delta \mathrm{S}(\mathrm{J} / \mathrm{mol} \mathrm{K})$ & $\Delta \mathrm{G}(\mathrm{kJ} / \mathrm{mol})$ \\
\hline \multirow{3}{*}{ Nitenpyram } & 1 & 288 & \multirow{3}{*}{11.388} & 64.52 & -7.193 \\
\hline & 1 & 303 & & 62.91 & -7.673 \\
\hline & 1 & 318 & & 61.62 & -8.209 \\
\hline \multirow{3}{*}{ Acetamiprid } & 1 & 288 & \multirow{3}{*}{-4.081} & 4.698 & -5.435 \\
\hline & 1 & 303 & & 9.205 & -6.870 \\
\hline & 1 & 318 & & 16.31 & -9.267 \\
\hline
\end{tabular}

THERMODYNAMIC PARAMETERS FOR THE ADSORPTION OF NITENPRYRAM OR ACETAMIPRID ONTO THE RESIN IN SINGLE COMPONENT SYSTEM 

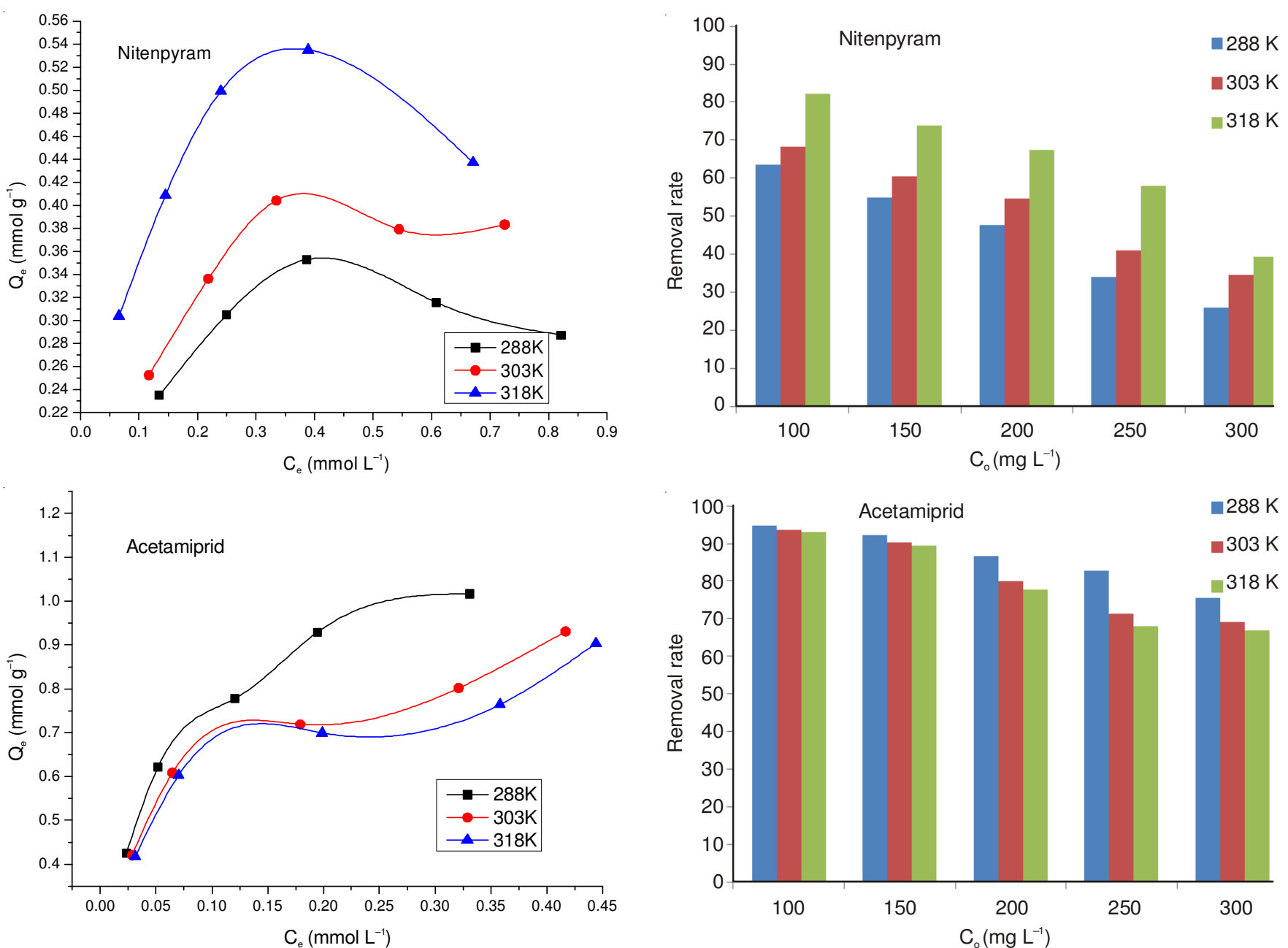

Fig. 3. Equilibrium adsorption isotherms of nitenpyram or acetamiprid in binary components system

Based on Fig. 5 and Table-3, the equilibrium adsorption isotherms of both nitenpyram and acetamiprid in binary components system were fitted better by Langmuir model. So the adsorption of nitenpyram and acetamiprid on the resin modified with proline was on the monolayer adsorption. There was the competition on adsorption site.

From Table-4, the adsorption capacity of acetamiprid and nitenpyram in binary components system were more than the adsorption capacity in single component system (nitenpyram or acetamiprid) on the resin at the same higher equilibrium concentration at $318 \mathrm{~K}$, which would be due to the cooperative effect and solute-solvent measurement replacement. When temperature was at $288 \mathrm{~K}, 313 \mathrm{~K}$, the capacity in binary components system was between nitenpyram and acetamiprid in single system, because of the competition on the adsorption locus, these molecules were organized in the arrangement out of disorder, according to Table-3. In binary components system the equilibrium adsorption isotherms could not be fitted by Freundlich and Langmuir model for individual adsorbate. The competitive adsorption was existed. Cooperative adsorption was existed at $318 \mathrm{~K}$.

Simultaneous adsorption in binary components system: For further testifying the above predominant mechanism, the influence of initial concentration on the adsorption capacity was demonstrated in Fig. 6. There was some drop in the adsor-

Fig. 4. Removal rate of nitenpyram and acetamiprid at different initial solute concentrations in binary components system

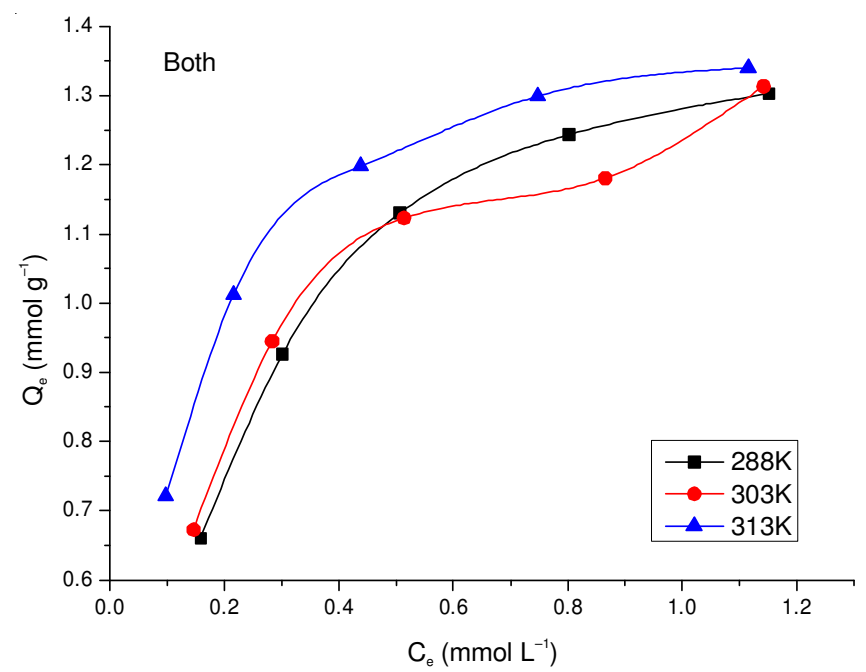

Fig. 5. Equilibrium adsorption isotherms of both nitenpyram and acetamiprid in binary components system

ption amount of acetamiprid with the increasing initial concentration of nitenpyram, but larger distinction for nitenpyram with the increasing initial concentration of acetamiprid, competitive adsorption phenomenon existed. The change of acetamiprid' concentration had greater effect on the adsorption of nitenpyram onto the resin modified with proline. 


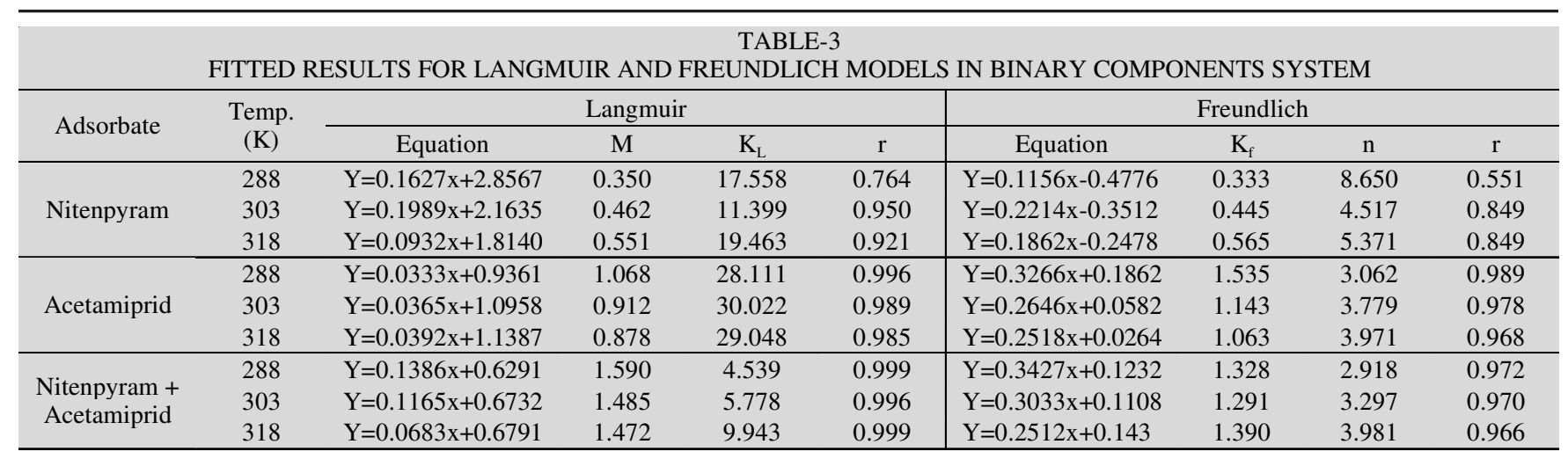

\begin{tabular}{|c|c|c|c|c|c|c|c|c|c|}
\hline \multicolumn{10}{|c|}{$\begin{array}{c}\text { TABLE-4 } \\
\text { CONTRASTIVE ANALYSIS OF THE ADSORPTIVE }\end{array}$} \\
\hline System & Adsorbate & Langmuir model & Temp. (K) & $\mathrm{C}_{\mathrm{e}}$ & $\mathrm{Q}_{\mathrm{e}}$ & $\mathrm{C}_{\mathrm{e}}$ & $\mathrm{Q}_{\mathrm{e}}$ & $\mathrm{C}_{\mathrm{e}}$ & $\mathrm{Q}_{\mathrm{e}}$ \\
\hline \multirow{6}{*}{ Single } & \multirow{3}{*}{ Nitenpyram } & $Y=0.1854 x+0.9027$ & 288 & 0.1 & 0.363 & 0.5 & 0.785 & 1.0 & 0.919 \\
\hline & & $Y=0.1398 x+0.8008$ & 303 & 0.1 & 0.455 & 0.5 & 0.925 & 1.0 & 1.063 \\
\hline & & $Y=0.1146 x+0.7624$ & 318 & 0.1 & 0.524 & 0.5 & 1.008 & 1.0 & 1.140 \\
\hline & \multirow{3}{*}{ Acetamiprid } & $Y=0.1052 x+0.4602$ & 288 & 0.1 & 0.661 & 0.5 & 1.491 & 1.0 & 1.769 \\
\hline & & $Y=0.1153 x+0.5668$ & 303 & 0.1 & 0.581 & 0.5 & 1.254 & 1.0 & 1.466 \\
\hline & & $Y=0.1207 x+0.7097$ & 318 & 0.1 & 0.522 & 0.5 & 1.051 & 1.0 & 1.204 \\
\hline \multirow{3}{*}{ Binary } & \multirow{3}{*}{$\begin{array}{l}\text { Nitenpyram + } \\
\text { Acetamiprid }\end{array}$} & $Y=0.1386 x+0.6291$ & 288 & 0.1 & 0.496 & 0.5 & 1.103 & 1.0 & 1.303 \\
\hline & & $Y=0.1165 x+0.6732$ & 303 & 0.1 & 0.544 & 0.5 & 1.104 & 1.0 & 1.266 \\
\hline & & $Y=0.0683 x+0.6791$ & 318 & 0.1 & 0.734 & 0.5 & 1.226 & 1.0 & 1.338 \\
\hline
\end{tabular}
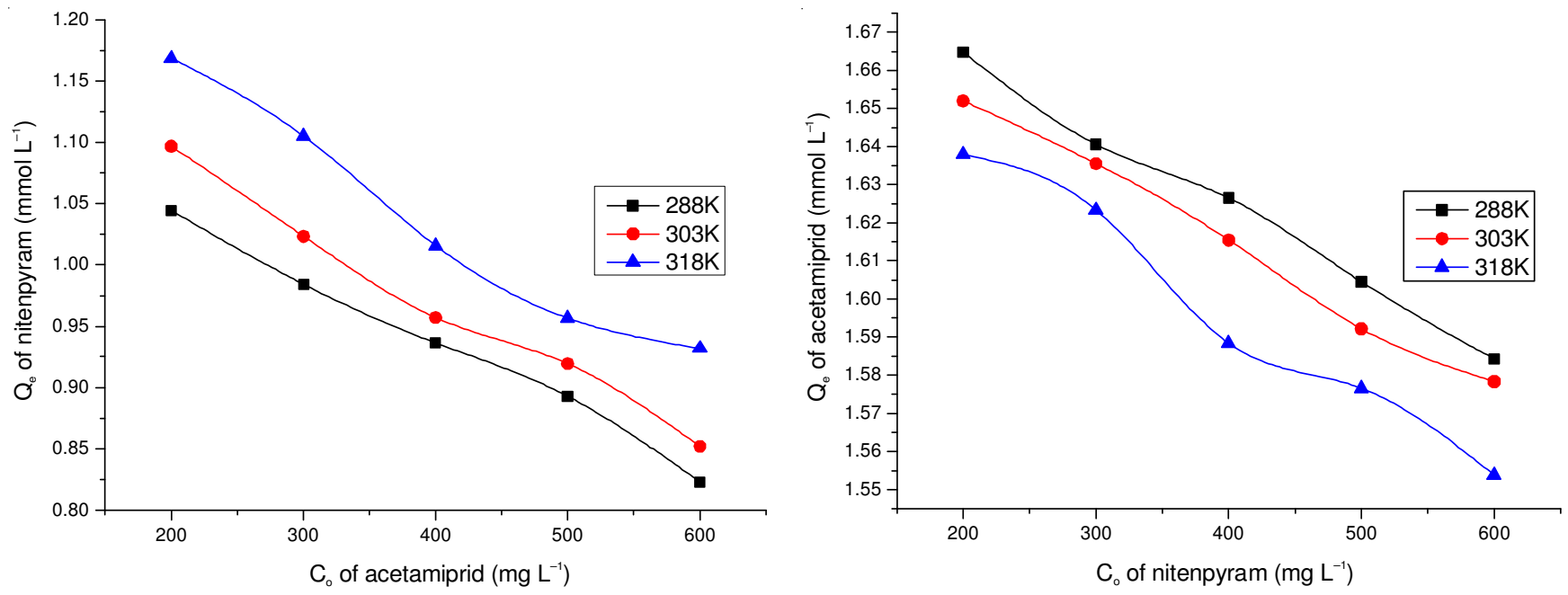

Fig. 6. Influence of initial concentration on the adsorption amount onto the resin from the binary components adsorptive environment

Selectivity index: Selectivity index often used to evaluate an adsorbent or an adsorptive process. If we define the distribution coefficient (solid-to-liquid) as:

$$
\mathrm{D}=\mathrm{Q}_{\mathrm{e}} / \mathrm{C}_{\mathrm{e}}
$$

Then the selectivity index of the first component has the following form:

$$
\mathrm{S}_{1 / 2}=\mathrm{D}_{1} / \mathrm{D}_{2}
$$

$\mathrm{D}_{1}$ and $\mathrm{D}_{2}$ represent the distribution coefficient of two solutes respectively ${ }^{12}$.

The selectivity indexes for the adsorption of acetamiprid onto the adsorbent tested are compared in Table-5, nitenpyram as the competitive component. It can be seen that the adsorption selectivity of acetamiprid on the resin is larger than one on lower temperature with lower concentrations, contributed to the larger difference in the adsorbent-solute interaction and solvent-solute interaction. Consequently, it is expected to apply the resin for the successful separation and recovery of acetamiprid from the water containing nitenpyram. The proposed technique has its practicability.

\section{Conclusion}

The adsorption of nitenpyram on the resin modified with proline was an endothermic process by the positive adsorption enthalpy and an exothermic process of acetamiprid with the negative adsorption enthalpy. Entropy change was giving a friendly behaviour to adsorption. The adsorption was fitted by Freundlich model better than Langmuir model, with higher linearity in single system. The resin had better absorbability for acetamiprid than for nitenpyram and the adsorption selectivity of acetamiprid was larger than one at lower temperature 
TABLE-5

SELECTIVITY INDEX OF ACETAMIPRID AND NITENPYRAM

\begin{tabular}{|c|c|c|c|c|c|c|c|c|c|}
\hline \multirow{2}{*}{$\begin{array}{c}\mathrm{C}_{0} \text { of } \\
\text { nitenpyram } \\
(\mathrm{mg} / \mathrm{L})\end{array}$} & \multirow{2}{*}{$\begin{array}{c}\mathrm{C}_{0} \text { of } \\
\text { acetamiprid } \\
(\mathrm{mg} / \mathrm{L})\end{array}$} & \multicolumn{3}{|c|}{ Temperature (K) } & \multirow{2}{*}{$\begin{array}{c}\mathrm{C}_{0} \text { of } \\
\text { nitenpyram } \\
(\mathrm{mg} / \mathrm{L})\end{array}$} & \multirow{2}{*}{$\begin{array}{c}\mathrm{C}_{0} \text { of } \\
\text { acetamiprid } \\
(\mathrm{mg} / \mathrm{L})\end{array}$} & \multicolumn{3}{|c|}{ Temperature (K) } \\
\hline & & 288 & 303 & 318 & & & 288 & 303 & 318 \\
\hline 200 & 400 & 18.781 & 13.074 & 5.456 & 400 & 200 & 2.403 & 1.974 & 1.155 \\
\hline 300 & 400 & 10.776 & 7.277 & 3.890 & 400 & 300 & 2.083 & 1.712 & 1.106 \\
\hline 400 & 400 & 8.941 & 5.838 & 4.056 & 400 & 400 & 1.494 & 1.277 & 0.944 \\
\hline 500 & 400 & 10.094 & 6.596 & 4.501 & 400 & 500 & 1.282 & 1.108 & 0.823 \\
\hline 600 & 400 & 8.392 & 6.173 & 3.760 & 400 & 600 & 1.132 & 0.948 & 0.645 \\
\hline
\end{tabular}

and at lower concentrations. A high removal rate of 45.56$82.66 \%$ was obtained for nitenpyram studied and the removal rate of acetamiprid was in the range of $48.77-86.23 \%$ in single component system. In binary components system the removal rate of acetamiprid was higher, lower for nitenpyram, because of competition in adsorption site. The equilibrium adsorption isotherms of both nitenpyram and acetamiprid in binary components system were fitted better by Langmuir model. So the adsorption of nitenpyram and acetamiprid on the resin modified with proline was on the monolayer adsorption in binary components system. But the cooperative effect existed at $318 \mathrm{~K}$. In additional studies, the competitive adsorption existed. The adsorption of acetamiprid onto the resin had just smaller change in the presence of nitenpyram, but the adsorption of nitenpyram was weakened obviously in the presence of acetamiprid. The adsorption selectivity of acetamiprid on the resin is larger than one on lower temperature with lower concentrations.

\section{ACKNOWLEDGEMENTS}

The work was financially supported by the National Natural Science Foundation of China (21201147) and the Council of Education of Jiangsu Province, China (12KJD150012), and sponsored by research fund of Key Laboratory for Advanced Technology in Environmental Protection of Jiangsu Province (No. AE201009), Thanks to the special fund for the Innovation and Transformation of Science and Technology Achievements of Jiangsu Province (BK2010037) and the project was supported by Science and Technology Achievement Industrialization in Universities of Jiangsu Province (JH10-43); sponsored by research fund of Jiangsu Provincial Key Laboratory of Coastal Wetland Bio resources and Environmental Protection (JLCBE12010).

\section{REFERENCES}

1. J.-G. Feng, X.-J. Zhang, C. Yu, W.-T. Chen, M.-L. Cai and X.-M.Wu, J. China Agric. Univ., 2, 220 (2013).

2. D.-B. Cheng, X.L.Yu and X.-M. Yu, J. Wuhan Instit. Technol., 9, 20 (2011).

3. X.H. Yuan, Y. Lei, L.M. Liu, W.C. Sheng and J. Hu, J. Jiangsu Univ., Natural Sci. Ed., 29, 410 (2008).

4. Z.H. Fei, Z.T. Liu, W.Z. Shi, Y.-L. Gu, Y.F. Sun, R. Xing and G.-C. Zhang, Acta Chim. Sin., 69, 2555 (2011).

5. S.S. Bayazit, I. Inci and H. Uslu, J. Chem. Eng. Data, 55, 679 (2010).

6. H.-G. Nam, K.-M. Park, S.S. Lim and S. Mun, J. Chem. Eng. Data, 56, 464 (2011)

7. A.M. Li, Q.X. Zhang, G.C. Zhang, J. Chen, Z. Fei and F. Liu, Chemosphere, 47, 981 (2002).

8. X. Wu, G. Zhang, H. Zhang, R. Xing and Z. Fei, Mater. Sci. Forum, 743-744, 636 (2013).

9. W. Zhang, J. Chen, Q. Zhang and B. Pan, Acta Polym. Sinica, issue no. 2, 213 (2006).

10. Z.-F. Xie, Y. Chen, Q. Yan, Z.-F. Tong and K.-Q. Yang, Chem.Eng. (China), 39, 44 (2011) (in Chinese).

11. F.Q. Liu, M.F. Xia, X.M. Cheng, H.S. Wu, Z.H. Fei and J.L. Chen, Environ. Pollut. Control, 8, 570 (2005) (in Chinese).

12. F.Q. Liu, Chinese J. Polym. Sci., 4, 373 (2005) (in Chinese).

13. S. Lou, Y.F. Liu, Q.Q. Bai and D.L. Di, Progr. Chem., 24, 1427 (2012) (in Chinese).

14. Z.-H. Fei, W.-Z. Shi and Z.-X. Li, Mater. Sci. Eng., 26, 64 (2010) (in Chinese). 